\title{
Intracoronary interleukin-6 levels in patients with ST segment elevation myocardial infarction treated with primary angioplasty and complicated with No Reflow
}

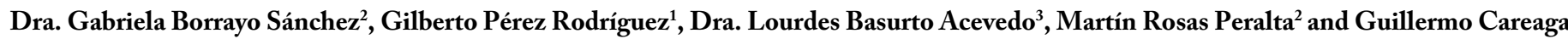 \\ Reyna $^{4}$ \\ ${ }^{1}$ Coordination of High Specialty Medical Units, Mexico \\ ${ }^{2}$ Hospital of Cardiology, IMSS National XXI Century Medical Center, Mexico \\ ${ }^{3}$ Unical Research Unit in Endocrine Diseases, National Medical Center, Mexico \\ ${ }^{4}$ Dirección, General Hospital de la Raza, IMSS, Mexico
}

\begin{abstract}
Objective: To evaluate the prognostic of interleukin 6 levels, in patients with acute myocardial infarction with No Reflow phenomenon.

Methods: Consecutive patients with acute ST elevation myocardial infarction diagnosis, with $\leq 12$ hours of evolution, and treated with primary angioplasty were included. The intracoronary interleukin 6 was measured before and after the procedure. The patients were classified into two groups: group I (Success or Reflow) and II (Failure or No Reflow) respectively. The early outcome variables were evaluated during the hospitalization.

Results: A total of 45 patients were studied, the average age was $62 \pm 11$ years, 26 patients in the group I, and 19 in the group II, without differences in the traditional risk factor, or in the evolution time. Compared to group 1, the complications were more frequent in the group II, compared to group I: hypotension (7.7\% vs. $63 \%$, $\mathrm{p}<0.0001)$, arrhythmias $(7.7 \%$ vs. $47 \%, \mathrm{p}=0.017)$ y hospital death $(0 \%$ vs. $32 \%, \mathrm{p}=0.001)$. The ejection fraction was lower in the group II (45.6 $\pm 9.2 \%$ vs. $34.8 \pm 11.3 \%$, $\mathrm{p}=0.009)$. The interleukin 6 levels were higher in the group II $(8.7 \pm 6.4$ vs. $16.8 \mathrm{pg} / \mathrm{mL}, \mathrm{p}=0.032)$.

Conclusion: The levels of Interleukin 6 intra-coronary are associated with the phenomenon of No Reflow, plus complications and early death.
\end{abstract}

\section{Introduction}

Worldwide, ischemic heart diseases are a public health problem because of their impact on morbidity and mortality. The World Health Organization predicts for the next two decades approximately 23.5 million deaths due to cardiovascular diseases, mainly acute myocardial infarction (AMI) worldwide [1]. In Mexico, the INEGI registered in 2013, 109,309 deaths due to this cause [2]. The OECD considers the mortality in subjects over 45 years old as an indicator of care quality (average 7.9). However, it placed Mexico with the highest fatality rate in 2013 (27.2). In the United States of America mortality affects 195 people per 100,000 [3] and the cost was more than 150 billion dollars [4], 72\% was attributed to the costs of hospitalization [5]. The European Union also reported the cardiovascular diseases as the leading cause of death, with a care annual investment up to 169 billion euros [6].

Both costs and clinical outcomes are related with timely diagnosis and treatment at the emergency department, by opening the culprit artery involved in the myocardial infarction with percutaneous coronary intervention (PCI) or fibrinolytic therapy (FT). The first real world study in the IMSS (RENASCA IMSS) included 2398 patients, [7] most of them with ST Segment Elevation Myocardial Infarction (STEMI) and high risk [7]. Only $42 \%$ were treated with FT and $8 \%$ with primary PCI, the remaining 50\% did not receive any reperfusion therapy. The reported mortality was $8 \%$, and heart failure more than $30 \%$. This data indicates the challenge for treating this disease.

In a meta-analysis of 23 studies with 7,739 patients, Keeley, and
Cols [8] demonstrated strong benefits with PCI, such as lower early mortality, less reinfarction and recurrent ischemia. Long-term, the benefit was shown with the same trend in mortality, nonfatal myocardial infarction, and recurrent ischemia [8]. The placement of drug eluting Stent reduced the risk of intervention compared to conventional Stent $(\mathrm{p}<0.001)$ [9]. Although the balance is tipped in favor of primary PCI with stenting, hospitals that perform this procedure 24 hours a day, 365 days a year, are required. That would also include an interdisciplinary group with sufficient experience to do it at the right time. Reperfusion injury occurs after restoring the circulation in previously ischemic heart cells due to the release of oxygen radicals, intracellular calcium accumulation and alterations in cellular metabolism [10]. It is a microvascular damage phenomenon, and is mediated by leukocyte activation and pro-inflammatory markers (interleukin 1 and 6) [11] are entered. In addition, it is associated with Left Ventricular Function damage, which can directly increase morbidity and mortality $[10,11]$.

Correspondence to: Gabriela Borrayo Sánchez, Cuauhtémoc 330, Col. Doctores, Del. Cuauhtémoc, CP 06725, Mexico City, Mexico, Tel: 562769 00, ext. 22014 and 22000; E-mail: gborrayos@yahoo.com.mx , gabriela.borrayo@imss.gob.mx

Key words: Interleukin 6; acute myocardial infarction; No-reflow; primary angioplasty; reperfusion injury

Received: January 28, 2017; Accepted: February 26, 2017; Published: February 28,2017 

with No Reflow

Some strategies have been used to reduce reperfusion injury such as use of adenosine [12] and thrombus aspiration [13]. However, pathophysiology is complex and mechanisms to attach appropriate therapies has not been clearly established. There are few studies focused on identifying this context. In a study of 42 patients with unstable angina or STEMI, treated with PCI, a, increase of $76 \%$ in the level of intracoronary IL- 6 was identified, compared to the level in the aorta [14]. In a previous study by our group, the prognostic value of the IL6 levels for major cardiovascular events was evaluated for the first time in 97 patients with STEMI in the first 24 hours of onset of symptoms; patients with IL6 increased $>20 \mathrm{pg} / \mathrm{mL}$ had more major cardiovascular events (arrhythmias, angina, heart failure, nonfatal reinfarction and death) in-hospital, $\mathrm{RR} 1.59,\left(\mathrm{CI}_{95 \%}, 1.16-2.19\right)$ and more mortality, $\mathrm{RR} 1.16,\left(\mathrm{CI}_{95 \%} 1.02-1.31\right)$. Within the independent factors for cardiovascular events the concentration of IL6>20 pg/mL [15] was found.

Due to the complexity of the No Reflow phenomenon and its implications for the patients' prognosis, our objective was to evaluate the IL6 levels prognosis as a serum marker of the No Reflow phenomenon, and early complications in patients with STEMI diagnosis.

\section{Methods}

Consecutive patients of both genders, from 18 to 80 years old diagnosed with STEMI according to the AHA/ACC/ESC international criteria, from any location, entered to Hemodynamics service, indicated for primary angioplasty, and later to the Cardiovascular Intensive Care Unit of the Unidad Médica de Alta Especialidad, Hospital de Cardiología del Centro Médico Nacional Siglo XXI were studied. Patients with kidney failure, apparent infection, cardiomyopathy, valvular heart disease or congenital disease were not included. The subjects were divided into two groups: Group I with successful reperfusion and Group II with No Reflow phenomenon (not successful reperfusion). Early outcome variables were: recurrent ischemia, arrhythmias, hypotension, bradycardia, atrioventricular block, left ventricular damage, and death. During the usual angioplasty procedure, blood sample was obtained for determination of IL-6. The samples were centrifuged at $3000 \mathrm{rpm}$ for 15 minutes at $4^{\circ} \mathrm{C}$ and stored at $-70^{\circ} \mathrm{C}$ until the assay was performed. IL-6 concentration was determined by the chemiluminescence technique on the IMMULITE 1000 analyzer, using commercial kits from Diagnostic Products Corporation (Los Angeles, CA).

The study protocol was approved by the Research Committee of the Instituto Mexicano del Seguro Social. The participants were informed and signed the corresponding consent form.

\section{Statistical analysis}

Dichotomous variables were analyzed with $\mathrm{X}^{2}$ test or Fisher exact test, for the variables with normal distribution interval, Student $t$ was used. Interleukin 6 levels were evaluated with ROC Curve. Relative Risk $(\mathrm{RR})$ was calculated with a $95 \%$ confidence interval $\left(\mathrm{CI}_{95 \%}\right)$. P-value was considered as significant when $<0.05$.

\section{Results}

45 patients were studied, 26 in group I (successful reperfusion), and 19 in group II (No Reflow), with average age $62 \pm 11$ years, no differences in risk factors (diabetes, systemic arterial hypertension, smoking and dyslipidemia) were observed between the two groups (Table 1). Time of onset of symptoms was similar in both groups (6.4 \pm 3 vs. $5.1 \pm 3$ hours, $\mathrm{p}=0.465)$, the posterior-inferior infarct location with right ventricle involvement was more frequent in group II $(\mathrm{p}=0.02)$.
Table 1. Basal characteristics of the STEMI patients treated with Primary PCI.

\begin{tabular}{|l|c|c|}
\hline \multicolumn{1}{|c|}{ Variables } & $\begin{array}{c}\text { Group I (Reflow) } \\
\text { (n=26) }\end{array}$ & $\begin{array}{c}\text { Group II (No Reflow) } \\
\text { (n=19) }\end{array}$ \\
\hline Age (years) & $62.4 \pm 11.6$ & $62.6 \pm 10$ \\
\hline Gender M/F (\%) & $84.6 / 15.4$ & $73.7 / 26.3$ \\
\hline Risk Factors & & \\
\hline Smoking (\%) & 81 & 79 \\
\hline Hypertension (\%) & 54 & 68 \\
\hline Diabetes (\%) & 50 & 63 \\
\hline Dyslipidemia (\%) & 48 & 61 \\
\hline Medical History & & 42 \\
\hline Previous STEMI (\%) & 23 & 21 \\
\hline Previous Angina (\%) & 19 & 0 \\
\hline Previous CABG (\%) & 0 & 5 \\
\hline Previous PCI (\%) & 0 & \\
\hline
\end{tabular}

No significant differences between the groups were observed.

Table 2. Hemodynamic, echocardiographic, and biochemical characteristics in each study group.

\begin{tabular}{|c|c|c|}
\hline Variables & $\begin{array}{c}\text { Group I (Reflow) } \\
(\mathrm{n}=26)\end{array}$ & $\begin{array}{c}\text { Group II (No Reflow) } \\
(\mathrm{n}=19)\end{array}$ \\
\hline \multicolumn{3}{|l|}{ Hemodynamic Data } \\
\hline Systolic Blood Pressure (mmHg) & $117 \pm 22.3$ & $99.3 \pm 20.8^{*}$ \\
\hline Diastolic Blood Pressure $(\mathrm{mmHg})$ & $72.7 \pm 15.2$ & $64.0 \pm 14.0$ \\
\hline Heart rate $(\mathrm{lpm})$ & $78 \pm 14$ & $92 \pm 14^{* *}$ \\
\hline Breathing rate (rpm) & $20 \pm 3$ & $18 \pm 2$ \\
\hline \multicolumn{3}{|l|}{ Echocardiographic Data } \\
\hline Diastolic diameter (mm) & $47.3 \pm 4.6$ & $57.6 \pm 16.9$ \\
\hline Systolic diameter (mm) & $34.4 \pm 6$ & $44.6 \pm 11.3^{*}$ \\
\hline LVEF (\%) & $45.6 \pm 9.2$ & $34.8 \pm 11.3^{* *}$ \\
\hline AVF (\%) & $25.5 \pm 5$ & $15.5 \pm 2$ \\
\hline RVEF (\%) & $50.7 \pm 22.9$ & $47.3 \pm 17.2$ \\
\hline \multicolumn{3}{|l|}{ Biochemical Determinations } \\
\hline Hemoglobin $(\mathrm{g} / \mathrm{dL})$ & $13.8 \pm 2.3$ & $13.6 \pm 2.1$ \\
\hline Platelets $\left(\times 10^{9} / \mathrm{L}\right)$ & $221.4 \pm 60.8$ & $229.2 \pm 63$ \\
\hline Fibrinogen (mg/dL) & $471 \pm 157$ & $506 \pm 177$ \\
\hline Leucocytes $\left(\times 10^{3} / \mathrm{L}\right)$ & $10.5 \pm 3.6$ & $14.02 \pm 5.7^{*}$ \\
\hline Glucose (mg/dL) & $199.1 \pm 81.9$ & $253.9 \pm 119$ \\
\hline Urea (mg/dL) & $41.1 \pm 19.3$ & $50.7 \pm 25.9$ \\
\hline Creatinine (mg/dL) & $0.94 \pm 0.5$ & $1.22 \pm 0.66$ \\
\hline CPK (U/L) & $2667 \pm 2534$ & $3087 \pm 2697$ \\
\hline CK-MB (U/L) & $189.2 \pm 150$ & $207.6 \pm 173$ \\
\hline Troponin I (ng/dL) & $17.5 \pm 12.2$ & $24.46 \pm 9.9$ \\
\hline C-reactive protein $(\mathrm{mg} / \mathrm{L})$ & $3.3 \pm 3.1$ & $5.38 \pm 4.8$ \\
\hline
\end{tabular}

$* \mathrm{p}<0.05, * * \mathrm{p}<0.01$

LVEF: Left Ventricle Ejection Fraction, RVEF: Right Ventricle Ejection Fraction.

The most frequent culprit artery in infarction was the right coronary artery, with no differences in both groups. Compared with group $\mathrm{I}$, left ventricular ejection fraction (LVEF) was significantly lower in group II ( $45.6 \pm 9.2 \%$ vs. $34.8 \pm 11.3, \mathrm{p}=0.009)$ (Table 2$)$. No significant differences were found in the concentration of myocardial necrosis markers or c-reactive protein (Table 2).

Interleukin 6 levels were higher in group II $(8.73 \pm 6.4$ vs. $16.88 \pm$ $14.5 \mathrm{pg} / \mathrm{mL}, \mathrm{p}=0.032$ ) (Figure 1 ). Similarly, both IL6 post-angioplasty concentration $(11.9 \pm 13.6$ vs. $23.2 \pm 20.3 \mathrm{pg} / \mathrm{mL}, \mathrm{p}=0.03)$, and 24 hours' concentration $(20.4 \pm 6.8 v s .67 .3 \pm 46.9 \mathrm{pg} / \mathrm{mL}, \mathrm{p}=0.03)$ were higher in group II (No Reflow). The area under the curve for IL6, before and after the procedure, was 0.768 and 0.811 respectively. Clinical and electrocardiographic complications are shown in Table 3. Clinical complications occurred more frequently in group II. The 


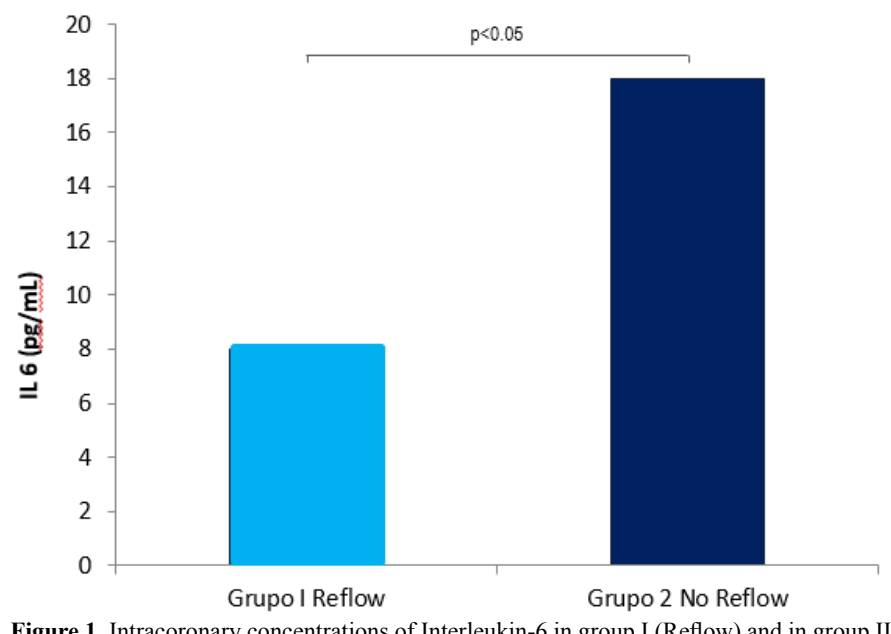

Figure 1. Intracoronary concentrations of Interleukin-6 in group I (Reflow) and in group II (Failure or No Reflow) are shown.

Table 3. Clinical and electrocardiogram complications in each study group of the STEMI patients treated with Primary PCI.

\begin{tabular}{|c|c|c|c|}
\hline Variables & $\begin{array}{c}\text { Group I } \\
\text { (Reflow) }(\mathrm{n}=26)\end{array}$ & $\begin{array}{l}\text { Group II (No } \\
\text { Reflow) }(\mathrm{n}=19)\end{array}$ & $\operatorname{RR}\left(\mathrm{CI}_{95 \%}\right)$, p-value \\
\hline Hypotension (\%) & 7.7 & 63 & $23(4-131), p<0.0001$ \\
\hline Bradycardia (\%) & 7.7 & 42 & $11(2-65), p=0.007$ \\
\hline Arrhythmias (\%) & 7.7 & 36.8 & $\begin{array}{l}8.9(1.5-51.4) \\
p=0.017\end{array}$ \\
\hline $\begin{array}{l}\text { Complete AV Block } \\
(\%)\end{array}$ & 3.8 & 31.5 & $\begin{array}{l}13(1.4-122) \\
p=0.012\end{array}$ \\
\hline $\begin{array}{l}\text { Ventricular Tachycardia } \\
(\%)\end{array}$ & 0 & 21 & NA, $p=0.018$ \\
\hline $\mathrm{KK} \geq 2(\%)$ & 19 & 52.6 & $\begin{array}{l}4.6(1.23-17.6), \\
p=0.027\end{array}$ \\
\hline Death & 0 & 31.5 & $\mathrm{NA}, \mathrm{p}=0.001$ \\
\hline
\end{tabular}

risk of presenting arterial hypotension, arrhythmias, bradycardia, and complete atrioventricular block was higher in the No Reflow group (Table 3). In-hospital mortality in group I was $0 \%$ while in group II it was $32 \%, \mathrm{p}=0.001$. A direct correlation between the levels of IL6 pre $(\mathrm{r}=0.460, \mathrm{p}=0.002)$ and post $\mathrm{PCI}(\mathrm{r}=0.536, \mathrm{p}<0.0001)$ was observed with the presence of No Reflow, as well as the presence of Killip $>2(\mathrm{r}=0.548$, $\mathrm{p}=0.003)$, and was reversed with low LVEF $(\mathrm{r}=-0.427, \mathrm{p}=0.019)$.

\section{Discussion}

The phenomenon of No Reflow has different denominations. It is also known as reperfusion injury or recently microvascular obstruction; It is considered to be multifactorial and the pathophysiological conditions that contribute to its presence are not clearly known. It has been described that there is a period of ischemia and that abruptly the opening of the culprit artery triggers the liberation of free radicals and the inflammatory process that deteriorates the microvascular perfusion and the functioning of the myocytes, besides the embolization and formation of new blood clots in the atherothrombotic context; However, it can be that this environment already exists prior to reperfusion, so the knowledge in this field is still under development $[11,14]$.

It has been observed that it is more frequent in STEMI than in unstable angina, in programmed PCI in chronic patients, the factors that intervene between them are different, so the therapeutic approach knowledge-based has not been able to be conclusive. What is proven is that these No Reflow patients have more frequent adverse events, including death, so it is important to develop strategies to prevent it, which currently occupies the interest of many investigations. In this first report with 45 consecutive patients, the intracoronary concentration of IL-6 in the culprit artery in STEMI was measured for the first time, and the association with the No Reflow phenomenon was established. The time of evolution was not different between groups, however, the time in reperfusion was prolonged, considering that the best results are observed when it is performed in the first hour.

Despite the study' sample size, a high percentage of No Reflow was identified in a reference hospital because patients arrived after the first two hours of symptom evolution, which was shown to be beneficial for any of the reperfusion strategies in the CAPTIM study [16]. The No Reflow phenomenon has been associated with major cardiovascular events, including clinical complications such as hypotension that does not reflect myocardial damage and electrical complications such as bradycardia, ventricular arrhythmias, and complete atrioventricular block, which are secondary to cell damage and membrane instability $[16,17]$. The ejection fraction was significantly lower in group II, as demonstrated in a previous work by our research group, in which IL6 levels in serum were determined during the first 24 hours, which indicates that there is microvascular and functional myocardium damage, reducing the rate of left ventricular mobility $[15,17]$. It was also identified that both IL6 levels $>20 \mathrm{pg} / \mathrm{mL}$ and Killip classification are independent factors for major cardiovascular events [15]. In this study, the No Reflow phenomenon was more frequent in right ventricle infarction, which is an original contribution, and even can be stratified in these high-risk patients not only by the electrical extension to the right ventricle but also by the inflammatory condition, which predisposes to No Reflow. IL-6 levels were higher in group II, even above $99^{\text {th }}$ percentile, and above the serum level reported. Probably due to the hours of evolution and the results obtained, since it is important to start the reperfusion treatment with greater opportunity and to initiate the adjunctive therapy before PCI. In this sample, thrombus aspiration was not performed yet, nor was established as currently the adjunct antiplatelet therapy. All this mentioned, forces us to carry out preventive strategies before elective PCI, it is convenient to evaluate thrombus aspiration and optimal antiplatelet treatment. However, there are still many topics to investigate about the benefit in STEMI patients that are treated with primary PCI with different preventive strategies, since it is considered an epiphenomenon that reflects further myocardial damage. In the TAPAS [13] study, thrombus aspiration was used to prevent the No Reflow phenomenon. After primary PCI, a significant reduction in myocardial damage and adverse events was achieved. There are no studies with sufficient sample size comparing the different strategies to have strong data, some are still recommendations of expert groups and few have a greater level of evidence, since there are no controlled clinical trials that strengthen the treatment guidelines. The mechanical effect of preconditioning with a jet of balloon [17] before PCI in stable patients has also been implemented; however, in STEMI patients it could delay the opening of the culprit artery, so its role is not clear in these patients.

Although, as mentioned before, there is interest in mechanical strategies to avoid embolism (thrombus aspiration and distal protection devices), the knowledge of cardio protection through intracellular signaling pathways has caught the attention of researchers, 
since they are considered the final pathway in cell damage. Some of the agonists that may confer cardio protection include the use of adenosine, verapamil and nitric oxide, in contrast there is controversy in the role of some cytokines such as bradykinin, tumor necrosis factor alpha and IL-6 [12,19]. Signaling pathways include the opening of the sarcolemma and/or Mitochondrial ATP-Dependent Potassium Channels, and the activation of kinase (AKT and ERK-1/2, protein kinase $\mathrm{C}$ and $\mathrm{G}$ ) blocking the final pathway of Mitochondrial transition [18]. Recently a specific mitochondrial peptide (Bendavia) has been developed as a cardio protector in an experimental level, and reduction in the infarction size and ischemic area was found, so it is considered that could protect against reperfusion damage in experimental animals [19]. Other drugs such as cyclosporine and pentoxifylline are under study. But the mechanisms of action and clinical effect have not yet been established in STEMI patients.

Some of the results of this study are original. Therefore, additional studies with a larger sample size will be required to confirm if there is a causal association between the No Reflow phenomenon, intracoronary IL-6 concentration, and complications in STEMI patients. Studies that allow to identify if the increase of IL-6 in the patient with No Reflow is a consequence or a cause of hypotension, or is related to reperfusion damage, are also necessaries.

\section{Conclusions}

Patients with STEMI diagnosis treated with primary angioplasty and complicated with NO Reflow phenomenon present higher levels of IL-6, have more clinical complications and less ejection fraction. As original information, data from this study suggest that elevation of IL-6 participates in the pathophysiological mechanisms of the No Reflow phenomenon. On the other hand, complications due to heart failure and in-hospital mortality were observed more frequently in the No Reflow group, so these patients should be considered as high risk patients.

\section{Conflict of interest}

The authors involved in this research do not have any conflict of interest of any kind.

\section{References}

1. WHO's Annual compilation of data from its 193 Member States, including a summary of progress towards the health-related Millennium Development Goals and Targets 2011.

2. Instituto Nacional de Estadística, Geografía e Informática. Epidemiología de la defunción poblacional. México, INEGI 2010 www.inegi.gob.mx

3. Kenneth D, Kochanek MA, Jiaquan X, Sherry L, Murphy BS, et al. (2011) Deaths: Preliminary data for 2009. National Vital Statistics Reports 59: 1-51.
4. Rosamond W, Flegal K, Furie K, Go A, Greenlund K, et al. (2008) Heart disease and stroke statistics--2008 update: a report from the American Heart Association Statistic Committee and Stroke Statistics Subcommittee. Circulation 117: e25-146. [Crossref]

5. Etemad LR and McCollam PI. (2005) Total first-year costs of acute coronary syndrome in a managed care setting. J Manag Care Pharm 11: 300-306. [Crossref]

6. Leal J, Luengo-Fernández R, Gray A, Petersen S, and Rayner M. (2006) Economic burden of cardiovascular disease in the enlarged European Union. Eur Heart $J 27$ : 1610-1619. [Crossref]

7. Borrayo-Sánchez G, Madrid-Miller A, Arriaga-Nava R, Ramos-Corrales MA, GarcíaAguilar J, et al. (2010) Riesgo estratificado de los síndromes coronarios agudos. Resultados del primer RENASCA-IMSS. Rev Med Inst Mex Seguro Soc 48: 259-264.

8. Keeley EC, Boura JA, Grines CL. (2003) Primary angioplasty versus intravenous thrombolytic therapy for acute myocardial infarction : a quantitative review of 23 randomized trials. Lancet 361: 13-20. [Crossref]

9. Kastrati A, Dibra A, Spaulding C, Laarman GJ, Menichelli M, et al. (2007) Metaanalysis of randomized trials on drug-eluting stents vs. bare-metal stents in patients with acute myocardial infarction. Eur Heart J 28: 2706-2713. [Crossref]

10. Férez SS, Márquez MF, Peña MA, Ocaranza R, de la Peña E, et al. (2004) Daño miocárdico por reperfusión. Rev Esp Cardiol 57: 9-21.

11. Collard CD and Gelman S. (2001) Pathophysiology, clinical manifestations, and prevention of ischemia-reperfusion injury. Anesthesiology 94: 1133-1138. [Crossref]

12. Quintana M, Kahan T and Hjemdahl P. (2004) Pharmacological prevention of reperfusión injury in acute myocardial infarction: A potential role for Adenosine as a therapeutic agent. Am J Cardiovasc Drug 4: 159-167. [Crossref]

13. Svilaas T, Vlaar PJ, van der Horst IC, Diercks GF, de Smet BJ, et al. (2008) Thrombus aspiration during primary percutaneous coronary intervention. $N$ Engl J Med 358: 557567. [Crossref]

14. Maier W, Altwegg L, Corti R, Gay S, Hersberger M, et al. (2005) Inflammatory markers at the site of ruptured plaque in acute myocardial infarction. Circulation 111 : $1355-1361$

15. Borrayo SG, Pacheco BA, Mendoza VL, Isordia SI, Argüero SR, et al. (2010) Valor pronóstico de los niveles de IL-6 en pacientes con infarto agudo de miocardio con elevación del ST. Cir Ciruj 78: 25-30.

16. Bonnefoy E, Steg PG, Boutitie F, Dubien PY, Lapostolle F, et al. (2009) Comparison of primary angioplasty and pre-hospital fibrinolysis in acute myocardial infarction (CAPTIM) trial: a 5 year follow up. Eur Heart J 30: 1598-606. [Crossref]

17. Borrayo G, Careaga G, Muro CJ, Autrey A, Pérez P, et al. (2003) Valoración de la función ventricular derecha mediante ecocardiografía de contraste en pacientes con infarto agudo de miocardio. Rev Esp Cardiol 56: 175-180.

18. Kloner RA. (2009) Clinical application of remote ischemic preconditioning. Circulation 119: 776-778. [croosref]

19. Heusch G, Boengler K, Schulz R. (2008) Cardioprotection: nitric oxide, protein kinases, and mitochondria. Circulation 118: 1915-1919. [Crossref]

20. Kloner RA, Hale SL, Dai W, Gorman RC, Shuto T, et al. (2012) Reduction of ischemia/ reperfusion injury with Bendavia, a mitochondria-targeting cytoprotective peptide. $J$ Am Heart Assoc 1: e001644. [Crossref]

Copyright: (C2017 Sánchez DGB. This is an open-access article distributed under the terms of the Creative Commons Attribution License, which permits unrestricted use, distribution, and reproduction in any medium, provided the original author and source are credited. 